\title{
UMA PROFESSORA INICIANTE APRENDENDO A ALFABETIZAR: PROCESSOS FORMATIVOS E SABERES DOCENTES NA CORDA BAMBA
}

\author{
UNA PROFESORA PRINCIPIANTE APRENDIENDO A ALFABETIZAR: PROCESOS \\ FORMATIVOS Y SABERES DOCENTES EM LA CUERDA FLOJA
}

\author{
A BEGINNER TEACHER LEARNING TO LITERACY: EDUCATIONAL PROCESSES \\ AND TEACHER KNOWLEDGES IN THE TIGHTROPE
}

Taís Aparecida de MOURA ${ }^{1}$

Maria Regina GUARNIERI ${ }^{2}$

RESUMO: Este artigo decorre de uma pesquisa de mestrado na área de educação escolar e tem como objetivo refletir sobre os saberes que envolvem a aprendizagem da docência para alfabetizar, considerando as vivências de uma professora iniciante em uma turma do $1^{\circ}$ ano do Ensino Fundamental. Para tanto, desenvolveu-se uma pesquisa qualitativa, de base empírica, com observações em sala de aula e entrevista. Os dados obtidos foram organizados no eixo temático "A natureza do processo de alfabetização" e analisados nas categorias: 1) concepção de alfabetização; 2) escolha dos métodos de alfabetização; 3) saberes docentes para alfabetizar. Os resultados apontaram a prática de alfabetização como um processo complexo, que se agrava diante da insuficiência de saberes adquiridos na formação inicial docente para ensinar a ler e a escrever. Portanto, este estudo é propositivo para problematizarmos os rumos da formação do professor alfabetizador, que aparenta estar no balanço de uma corda bamba.

PALAVRAS-CHAVE: Formação inicial docente. Início da docência. Práticas de alfabetização. Aprendizagem da docência. Saberes docentes.

RESUMEN: Este artículo se deriva de una investigación de maestría en el área de educación escolar y tiene como objetivo reflexionar sobre los saberes que involucran el aprendizaje de la docencia para alfabetizar, considerando las vivencias de una profesora principiante en una clase del $1^{o}$ año de la Enseñanza Fundamental. Para ello, se desarrolló una investigación cualitativa, de base empírica, con observaciones en aula y entrevista. Los datos obtenidos fueron organizados en el eje temático "La naturaleza del proceso de alfabetización" y analizados en las categorías: 1) concepción de alfabetización; 2) elección de los métodos de alfabetización; 3) saberes docentes para alfabetizar. Los resultados apuntaron la práctica de alfabetización como un proceso complejo, que se agrava delante de la insuficiencia de saberes adquiridos en la formación inicial docente para enseñar a leer y a escribir. Por lo tanto, este estudio es propositivo para problematizar los rumbos de la formación del profesor alfabetizador, que aparenta estar en el balance de una cuerda floja.

\footnotetext{
${ }^{1}$ Universidade Estadual de Campinas (UNICAMP), Campinas - SP - Brasil. Doutoranda pelo programa de Pósgraduação em Educação. ORCID: <http://orcid.org/0000-0001-5545-3531>. E-mail: tais.ap.moura@ hotmail.com ${ }^{2}$ Universidade de Araraquara (UNIARA), Araraquara - SP - Brasil. Professora Doutora do programa de PósGraduação em Processos de Ensino, Gestão e Inovação. ORCID: <http://orcid.org/0000-0002-7508-278X>. Email: mrguarnieri@terra.com.br
} 
PALABRAS CLAVE: Formación inicial docente. Inicio de la docencia. Prácticas de alfabetización. Aprendizaje de la docencia. Saberes docentes.

ABSTRACT: This article is based on a master's research in the area of school education and aims to reflect on the knowledge that involves teaching learning to read, considering the experiences of a beginner teacher in a class of the first year of Elementary School. For that, a qualitative, empirical research was developed, with observations in the classroom and interview. The data obtained were organized in the thematic axis "The nature of the literacy process" and analyzed in the categories: 1) conception of literacy; 2) choice of literacy methods; 3) Teaching skills for literacy. The results pointed to the practice of literacy as a complex process, which is aggravated by the insufficiency of knowledge acquired in the initial teacher training to teach reading and writing. Therefore, this study is propositive to problematize the directions of the formation of the literacy teacher, who appears to be in the balance of a tightrope.

KEYWORDS: Initial teacher training. Beginning of teaching. Literacy practices. Teaching learning. Teacher knowledges.

\section{Considerações introdutórias}

O presente trabalho decorre de uma pesquisa de mestrado ${ }^{3}$ realizada pelas autoras orientanda e orientadora respectivamente -, na área de educação escolar, em que se discutiu a respeito das práticas de alfabetização desenvolvidas por professoras alfabetizadoras com tempos de docência diferenciados, neste caso, uma professora iniciante e uma experiente na carreira docente.

Como recorte, o artigo tem por objetivo refletir sobre os saberes que envolvem a aprendizagem da docência para alfabetizar, considerando as vivências de uma professora iniciante, em uma turma do $1^{\circ}$ ano do Ensino Fundamental.

Nesse contexto, reconhecemos que a trajetória profissional e os processos formativos são atravessados por diferentes contornos, pois "o desenvolvimento profissional docente é marcado desde as primeiras brincadeiras na escola, lembranças da primeira professora, memórias enquanto estudantes e se estende por diferentes experiências entrelaçadas com a arte de educar" (MOURA; SILVA, 2014, p. 05).

Assim, de acordo com Vieira (2002) compreendemos que a escola é um emaranhado de forças que se complementam em um jogo de valores do qual participam diferentes atores e, por isso, aprender a ser professor é aprender a lidar com inúmeras forças existentes dentro e fora

${ }^{3}$ MOURA, T. A. Práticas de alfabetização de professoras alfabetizadoras iniciante e experiente no $1^{\circ}$ ano do Ensino Fundamental. 2016. 165 f. Dissertação (Mestrado em Educação Escolar) Universidade Estadual Paulista "Júlio de Mesquita Filho", Faculdade de Ciências e Letras, Câmpus de Araraquara, 2016. 
do contexto escolar, isto é, lidar com todas elas ao mesmo tempo. Por certo, Nóvoa (2000, p. 10) expõe que ser professor obriga a opções constantes, que cruzam a nossa maneira de ser com a nossa maneira de ensinar e que desvendam na nossa maneira de ensinar à nossa maneira de ser.

Desse modo, sustentadas por algumas inquietações, como: quais saberes tem embasado a atuação de uma professora iniciante na alfabetização? O que uma professora iniciante tem a dizer sobre a formação inicial docente voltada ao ensino da leitura e da escrita? buscaremos dar visibilidade para os debates que perpassam a formação de professores, ouvindo uma iniciante e movimentando outras e/ou novas reflexões nesse campo de estudo.

\section{Primeiros passos na corda bamba da docência}

[...] A esperança Dança na corda bamba de sombrinha E em cada passo dessa linha Pode se machucar

A esperança equilibrista Sabe que o show de todo artista Tem que continuar.

Música: "O bêbado e a equilibrista”, interpretada por Elis Regina. Composição de João Bosco e Aldir Blanc.

A docência é percebida de maneira distinta para os professores, no caso do início da carreira, diferentes autores, como Huberman (2000), Gonçalves (2000), Marcelo Garcia (1999), Guarnieri (1996), Lima (2006) se dedicaram a compreender essa fase do desenvolvimento profissional docente. Segundo Sisla e Moura (2014), o início da docência se configura como uma experiência marcada por muitos sabores, às vezes, podem ser doces, outrora, podem ter um paladar desagradável e amargo.

Assim, para caracterizarmos o iniciante, vamos dialogar a respeito do ciclo de vida profissional docente. Vale ressaltarmos que não há um consenso na literatura acerca da duração da etapa de iniciação na carreira, há autores que definem que essa fase profissional vai até os 03 primeiros anos de docência (HUBERMAN, 2000), de 01 a 04 anos de experiência (GONÇALVES, 2000) ou até de 01 a 05 anos (VEENMAN, 1988; TARDIF; LESSARD; LAHAYE, 1991). Todavia, aproximando-se da compreensão das últimas perspectivas 
anunciadas, vamos considerar como professor iniciante aquele com 01 a 05 anos de experiência docente.

No entanto, reconhecemos que mesmo um professor com mais tempo de experiência na carreira pode estar na posição de iniciante, na medida em que, seu ciclo de vida profissional oportunize que ele saia de sua zona de conforto. Por exemplo, um docente que esteja há muitos anos atuando no Ensino Fundamental, às vezes, pode precisar atuar em outra etapa de ensino como a Educação Infantil e, por consequência, isso também será um processo de iniciação, diferente do ingresso da carreira, mas que também trará novas sensações, sabores, angústias e descobertas.

Isso posto, destacamos que o processo que compreende as fases da carreira docente foi elaborado por Huberman (2000), no qual sugere um ciclo de vida profissional dos professores com um modelo sistemático de fases em que os docentes estão suscetíveis a vivenciar de forma sequencial, mas isso não é uma regra.

Por sua vez, esse autor nomeou a primeira fase da docência, como Entrada na Carreira, sugerindo que este período ocorre entre os 2-3 anos em que o professor inicia sua atuação, vai tateando e galgando seus primeiros passos na profissão caracterizados por dois aspectos fundamentais: o de sobrevivência e o de descoberta.

Nesse sentido, comumente o professor iniciante pode sofrer um "choque de realidade" (VEENMAN, 1988), termo usado no campo da formação de professores, para exprimir essa sensação de perturbação que o principiante tem sobre o cotidiano escolar, diante das suas impressões ideias com as reais da prática, da escola. Segundo Veenman (1988), as principais dificuldades enfrentadas pelos professores iniciantes referem-se à manutenção da disciplina $\mathrm{e}$ estabelecimento de regras de condutas na turma. Também existe uma preocupação com a motivação e trato com as características individuais dos alunos, assim como, apreensão no relacionamento com pais, alunos e comunidade e angústia na capacidade de ser competente como profissional.

Lima (2006), mediante várias pesquisas sobre professores iniciantes, também elencou algumas dificuldades sentidas por este grupo de professores que podem variar de docente para docente, em relação à quantidade, qualidade e intensidade. Para tanto, no início da carreira, essa autora indica que os professores se sentem inseguros e preocupados, o que acaba gerando uma submissão à opinião dos profissionais que eles consideram superiores ou mais experientes. As aprendizagens estão mais pautadas por processos de tentativas e erros, assim como existe um elevado conformismo às normas e regras sociais existentes na realidade da escola. Além disso, existe uma preocupação com o domínio dos conteúdos e uma experimentação de diversos 
modelos de ensino, sem uma reflexão apropriada sobre suas escolhas, existindo uma forte influência das experiências vividas enquanto estudantes.

Na percepção de Corsi (2005), as dificuldades encontradas pelos professores no início profissão são diversas e sentidas de maneiras diferentes. Em razão disso, tais dificuldades podem se transformar em reflexões e mudanças, mas em outros casos podem ser desencadeadoras de sentimentos fortes, chegando ao desencanto e, às vezes, levando o iniciante a romper com a profissão.

Em estudos mais recentes sobre a iniciação profissional, Papi e Martins (2010) sinalizam que é nesse período em que:

O professor se defrontará com a realidade que está posta e com contradições que nem sempre estará apto a superar. Seus conhecimentos profissionais são colocados em xeque e a postura que assume pode ir desde uma adaptação e reprodução muitas vezes pouco crítica ao contexto escolar e à prática nele existente, a uma postura inovadora e autônoma, ciente das possibilidades, dos desafios e dos conhecimentos profissionais que sustentam sua ação pedagógica (PAPI; MARTINS, 2010, p. 44).

Nessa direção, Gonçalves (2000) sinaliza que a entrada na docência consiste numa autêntica luta entre a vontade de se afirmar e o desejo de abandonar a profissão. É como se, nesse período, a pergunta "fico ou vou-me embora?" perpassasse diariamente os questionamentos dos principiantes.

Porém, apesar das dificuldades e descontentamentos, no início da docência notam-se muitas descobertas, que podem ser traduzidas como "o entusiasmo inicial, a experimentação, a exaltação do professor por estar, finalmente, em situação de responsabilidade (ter a sua sala de aula, os seus alunos, o seu programa), por se sentir colega num determinado corpo profissional" (HUBERMAN, 2000, p. 39).

De acordo com Lima et al. (2007) essa sensação de descoberta se traduz pelo sentimento de satisfação que o professor iniciante tem por passar a fazer parte de um corpo profissional, na qual experimenta a sensação de responsabilidade por algo que é "seu", ou seja, ele tem sua própria turma, se sente amado pelos estudantes, aprende coisas interessantes a partir de variadas fontes, como alunos, colega, formação e tantas outras.

Sendo assim, para essa autora, podem ser definidas como outras fontes de descobertas, os seguintes aspectos: possibilidade de aprender com os alunos; aprendizagem com os pares; formação acadêmica; afeto e acolhimento aos alunos; fazer escolhas. Concordamos com tais aspectos, mas, lembramos que sempre é possível aprender com os alunos, pois a aprendizagem da docência é contínua. 
Portanto, nesse movimento de sobreviver e descobrir entendemos que aprender a ser docente é vivenciar experiências como um/a equilibrista, isto é, em alusão à música cantada por Elis Regina, no início da carreira significa estar constantemente em uma corda bamba, mas, mesmo assim, o show tem que continuar.

\section{Metodologia: passos e movimentos da pesquisa}

A presente pesquisa foi desenvolvida com base numa abordagem qualitativa, a qual visa compreender a forma como as pessoas constroem o mundo à sua volta, no sentido de entender o que estão fazendo ou o que lhes está acontecendo, em termos que ofereçam uma rica visão sobre diferentes fenômenos sociais (GIBBS, 2009).

Bogdan e Biklen (1994) indicam cinco características da abordagem qualitativa. Nessa perspectiva, consideram que o ambiente natural é a fonte direta de dados e o pesquisador é seu principal instrumento. Também apontam que se trata de uma pesquisa descritiva, na qual o maior interesse do pesquisador é estudar o processo. Além disso, o significado que as pessoas atribuem às situações e à sua própria vida detém uma importância vital para o investigador que, ao analisar os dados, tende a seguir um processo indutivo, isto é, ele utiliza-se de múltiplas observações dos fenômenos, em que se partindo do específico busca-se conclusões de cunho generalizante.

Dadas às considerações sobre a abordagem de pesquisa qualitativa na educação, cabe mencionarmos, que o universo de estudo deste trabalho foi uma escola estadual de Ensino Fundamental do interior do estado de São Paulo, especificamente, com uma turma do $1^{\circ}$ ano do Ensino Fundamental e contou com a participação de uma professora iniciante, que há dois anos exerce a docência e estava vivenciando no ano de 2015 sua primeira experiência como alfabetizadora.

Nesse contexto, como instrumento de coleta de dados foram realizadas observações em sala de aula e uma entrevista semiestruturada. Essas observações ocorrem na turma que a iniciante atuava e perfizeram um total de 15 aulas assistidas, com duração de $4 \mathrm{~h} 30$ cada, durante o primeiro semestre de 2015. Já a entrevista com a participante, aconteceu fora do horário escolar e as perguntas foram organizadas em blocos temáticos tendo por foco as concepções, o planejamento e as práticas referentes à alfabetização. Destacamos que na análise, os depoimentos da participante estão identificados pelo termo Entrevista PI (professora iniciante). 
Os dados obtidos foram organizados em três eixos temáticos, sendo destacado para este artigo o eixo nomeado "A natureza do processo de alfabetização", em que compreendeu as seguintes categorias: 1) concepção de alfabetização; 2) escolha dos métodos de alfabetização; 3) saberes docentes para alfabetizar. Na sequência, segue análise de dados e resultados.

\section{A natureza do processo de alfabetização: dizeres e percepções de uma professora iniciante}

No eixo temático nomeado "A natureza do processo de alfabetização" buscamos investigar quais são as percepções de uma professora iniciante acerca dessa temática. Entre os comentários na entrevista, foi possível identificar uma queixa da professora quanto ao repertório de conhecimento adquirido na graduação para alfabetizar, que foi muito limitado. Segundo ela, apenas na disciplina de Didática que leu alguns textos sobre Piaget, Emília Ferreiro, mas de forma superficial, ou seja, chegou a aprender como fazer a sondagem das hipóteses da escrita, mas não teve nada específico sobre os métodos de alfabetização. Assim, ao ser questionada sobre qual é sua 'concepção de alfabetização', primeira categoria desse eixo, expressou-se da seguinte maneira:

Alfabetização, a ideia é que seje assim, você tem que dar uma base de ler e escrever para o aluno, ele tem que ter isso na cabeça, a escrita e a leitura. Antigamente a gente aprendia decorando as coisas agora eu acho que tem que ser o que as crianças trazem de fora pra gente ensinar, mas isso eu não sabia, eu tô sabendo agora. (Entrevista PI, 04/06/2015).

Pra mim, um aluno alfabetizado é que aquele sabe ler e escrever, não precisa ser corretamente, mas que tenha uma coesão no que ele está escrevendo e lendo. (Entrevista PI, 04/06/2015).

Ao analisarmos esses comentários é possível constatar que o conceito de alfabetização é relativizado, isso porque, a iniciante exprime a ideia de que se trata apenas de ensinar a criança a ler e escrever e que não se aprende decorando as coisas, mas com o que as crianças trazem de fora $^{4}$ para se ensinar.

Tal conceitualização pode ser considerada apropriada, pois de acordo com Soares (2014), etimologicamente o termo alfabetização não ultrapassa o significado de "levar à aquisição do alfabeto", ou seja, ensinar o código da língua escrita, ensinar as habilidades de ler e escrever e, portanto, não fazer essa consideração seria negar-lhe sua especificidade. Porém, ainda é possível atribuirmos um significado mais amplo para a alfabetização, pois sem dúvida

4 Interpretamos que esse "fora" refere-se à utilização das informações e vivências que as crianças trazem do seu cotidiano. 
“é um processo de representação de fonemas em grafemas, e vice-versa, mas é também um processo de compreensão/expressão de significados por meio do código escrito" (SOARES, 2014, p. 16).

Nessa análise, notamos que os depoimentos da entrevistada revelaram certa fragilidade em compreender o que é a alfabetização e, por consequência, isso acabou trazendo reflexos em sua prática como iniciante. Por exemplo, no que se refere à 'escolha dos métodos de alfabetização', observamos confusão quanto às escolhas adotadas, expressas por algumas falas:

Na época que eu fiz o magistério era cartilha ainda que se aprendia e que se ensinava o aluno, era o método tradicional. Eu aprendi a ensinar pelas famílias silábicas, que era o que eu estava fazendo, agora depois que eu fui ler o livro (Ler e Escrever) e me aperfeiçoar mais, então que eu vi que não era pela família silábica que se aprendia (Entrevista PI, 04/06/2015).

Eu não sei falar o que eu sou, eu acho que eu sou uma mistura de tudo, agora que tô mexendo só com o construtivismo, mas eu tava uma mistura de tudo, uma bagunça (Entrevista PI, 04/06/2015).

As observações feitas em sala de aula confirmaram que havia por parte da iniciante uma falta de conhecimento sobre os métodos de alfabetização, já que ela não apresentava ter um critério definido para selecionar as atividades, suas escolhas metodológicas eram uma "soma" de algumas experiências de seus processos formativos enquanto memórias de aluna e licencianda.

Então, a partir dos dizeres da iniciante e observações em sala de aula, compreendemos que ela foi criando seu próprio método para alfabetizar extraído de uma postura tradicional pautada na silabação e palavração, sendo que adicionava outros elementos originários da proposta construtivista, com base nas referências de algumas atividades do material Ler e Escrever ${ }^{5}$ que propõem, por exemplo, o trabalho oral e escrito com cantigas populares, adivinhas e parlendas para ensinar a leitura e a escrita.

Assim, em concordância com uma pesquisa feita por Carvalho (2008) com três professoras alfabetizadoras observamos que as práticas de alfabetização apresentam:

[...] ecos do construtivismo piagetiano de Ferreiro no discurso das pessoas entrevistadas, mas consideramos que as metodologias tradicionais, como palavração e o método fônico, são as bases de seu trabalho. Esses métodos não aparecem em estado puro: as professoras criam fusões ou sínteses, com elementos extraídos de métodos diversos, ou da própria experiência, às quais se juntam discretas influencias do construtivismo, como a admissão da escrita

${ }^{5}$ Destacamos que o material Ler e Escrever é utilizado como orientação didática na rede estadual do Estado de São Paulo. 
espontânea e um nível maior de tolerância em relação aos erros na escrita dos alunos (CARVALHO, 2008, p. 116-117).

Enfim, no caso da professora participante desta pesquisa, notamos que na condição de iniciante se sente despreparada para a alfabetização de crianças, sendo que na prática ela explora pouco o alfabeto, segue parcialmente o livro Ler e Escrever e faz muitas improvisações e tentativas metodológicas variadas.

Essa carência de conteúdo no que diz respeito ao objeto de conhecimento - leitura e escrita -, especificamente quando se é professora iniciante na alfabetização, vai ao encontro dos dados expostos, por exemplo, no trabalho de Marreiros (2011) que teve como foco a análise das concepções de aprendizagem da leitura e escrita e a relação existente entre a teoria estudada na formação inicial e continuada com a prática desenvolvida por professoras alfabetizadoras, considerando que os resultados de sua pesquisa evidenciaram uma fragmentação entre as dimensões teóricas e a prática realizada pelas professoras no processo de construção da alfabetização.

Por isso, em relação aos 'saberes docentes para alfabetizar', a iniciante julga ser necessário conhecer e ter domínio do conteúdo voltado para ensinar a leitura e a escrita no $1^{\circ}$ ano do Ensino Fundamental, ao afirmar que:

Para ser alfabetizadora ela tem que ter muita prática, do que a rede de ensino pede, tem que saber do que tá pedindo. As crianças têm que ler e escrever com a proposta do estado que é o Ler e Escrever e a professora tem que conhecer esse livro de "cabo a rabo" e mais um pouco para ela conseguir passar pro aluno. Eu não sei fazer, eu tô aprendendo agora. (Entrevista PI, 04/06/2015).

Reconhecemos que a prática é importante no desenvolvimento profissional, mas entendemos que os saberes para alfabetizar, vão além de aspectos práticos, afinal, pode-se definir o saber docente como um saber plural, formado pelo amálgama, mais ou menos coerente, de saberes oriundos da formação profissional e de saberes disciplinares, curriculares e experienciais." (TARDIF, LESSARD e LAHAYE, 1991, p. 36).

Ainda nessa categoria, a iniciante destaca que para ser uma alfabetizadora, se faz necessário conhecer as crianças, suas características nessa faixa etária (06 anos) e saber organizar o espaço da sala de aula com materiais adequados, conforme se nota nos depoimentos que seguem:

[..] Ela tem que saber mexer com a vida da criança pra conseguir fazer ela progredir dentro da escola, porque se a professora não souber disso ela desaba, ela tem que ensinar o que a criança vai procurar ali na escola, por exemplo, ela vem com o intuito de saber ler e aprender escrever, mas se é 
uma professora como eu, fiquei perdida, porque eu falava "o que eu vou ensinar?", eu não tinha base. A professora precisa ter um bom currículo de alfabetização, um bom preparo pra alfabetizar, porque senão ela não vai conseguir. (Entrevista PI, 04/06/2015).

A professora também precisa saber sobre essa criança que ela está trabalhando e muito. É porque as crianças não vêm todas formadinhas certinhas, vem cada uma de um jeito, umas já sabem, outras estão mais lá trás, então eu acho que o professor tem que saber a criança que tá trabalhando porque não vem uma classe toda certinha, tudo alfabética, é heterogênea a sala. (Entrevista PI, 04/06/2015).

Faz falta a professora ter um estudo sobre alfabetização. Ele tem que ter pelo menos assim, o método que o governo pede que é o construtivismo é muito amplo, tem muita coisa que a gente tem que saber. Eu não sabia nada, a sala tem que tá muito decorada, tem que ter muitos cartazes, muita coisa que a criança vê em casa, como rótulo de coisas, que é isso que ela vai aprendendo, o que ela traz do dia a dia dela, a professora tem que saber usar para alfabetizar. (Entrevista PI, 04/06/2015).

Por último, a iniciante associa com os saberes a questão do dom para a docência, sendo que em sua fala este foi um aspecto bastante enfatizado:

Eu acho que precisa ter muito dom pra ser uma alfabetizadora, muito dom, porque é uma criança que vem ali pra você ergue ela pro futuro, eu tô aprendendo esse dom agora. (Entrevista PI, 04/06/2015).

Segundo Enguita (1999) historicamente essa ideia de dom para a docência ou vocação para dar aula é compartilhada por alguns docentes e, neste caso, pela participante iniciante na carreira. Contudo, o autor ao analisar a ambiguidade da docência faz ponderações sobre a vocação cuja compreensão se define como um ato de devoção e até mesmo de penitência. Além disso, chama a atenção para outras características que definem a profissão docente e que perpassam entre a profissionalização à proletarização.

Em síntese, verificamos que as falas da professora iniciante nos dão pistas importantes para conhecermos o cotidiano de uma alfabetizadora e, ao mesmo tempo, nos movimenta a pensar sobre os saberes docentes, aspectos conceituais e formativos intrínsecos da carreira na alfabetização.

\section{Professora iniciante como uma equilibrista: algumas considerações para finalizar}

Ao darmos visibilidade para o professor iniciante nos estudos acadêmicos, verificamos que a entrada na carreira docente é um momento marcado por sentimentos contraditórios, isso 
porque o desejo de ação se entrelaça com o medo do julgamento do outro, tendo em vista que esse outro se refere aos pais, à equipe escolar, aos alunos e à comunidade.

Desse modo, compreendemos que o professor iniciante é aquele que chega cheio de vontade, cheio de expectativas e desejo de colocar em prática tudo que aprendeu nos últimos anos de estudo. É um anseio enorme de colocar a "mão na massa”, isto é, viver aquele momento único da docência que tem a ver com a responsabilidade de ter a sua primeira turma, um sentimento que lhe transborda a alma. Ao mesmo tempo, há a insegurança, medo e angústia porque o iniciante está preocupado com os pormenores e lidar com as frustações ou com as desventuras que possa vir a ter no cotidiano escolar é uma aprendizagem única para cada docente, pois depende de inúmeras variáveis como tempo, condições de trabalho e contexto escolar, conforme apontaram, por exemplo, estudos de Lima (2006), Papi e Martins (2010), entre outros.

E, em relação ao eixo temático analisado neste artigo - A natureza do processo de alfabetização -, observamos que ao citar seu entendimento sobre a concepção de alfabetização e o que considera um aluno alfabetizado, a professora iniciante faz uso de um discurso padrão, definindo que alfabetizar é levar à aquisição da leitura e da escrita. Porém, para ela ser alfabetizado significa que basta saber ler e escrever, ainda que não seja de forma convencional.

Do ponto de vista dos métodos de alfabetização, constatamos que a iniciante em suas práticas pedagógicas mescla os métodos tradicional e construtivista. E, quanto aos saberes docentes necessários para alfabetizar, ela afirma que é imprescindível conhecer os conteúdos voltados para a alfabetização, no entanto, realiza uma queixa constante em relação à insuficiência de saberes adquiridos na graduação para ensinar a ler e a escrever.

Contudo, a conclusão apontada de que os professores têm carência quanto ao repertório de conhecimento adquirido em relação à alfabetização, não é novidade nos estudos sobre formação docente (GUARNIERI, 1996; SCHEFFER, 2008; POWACZUK, 2009). Ao mesmo tempo, afirmar que o curso de Licenciatura em Pedagogia não consegue abordar adequadamente os conteúdos relacionados aos anos iniciais do Ensino Fundamental também já foi constatado, de modo que, na percepção de Giovanni (2005) a formação profissional e o próprio exercício da profissão não tem propiciado aos professores a capacidade de indagar e refletir sobre a docência.

Por isso, para sermos propositivas, ressaltamos que é preciso existir maior investimento por parte dos formadores de professores nas questões que competem às tarefas que o docente deve executar em sala de aula. Os iniciantes precisam ter consciência do que devem fazer para ensinar a leitura e a escrita, devem aprender a planejar o conteúdo, organizar o espaço da classe, 
entre outras tarefas. Cursos de formação continuada são importantes para ampliar e afunilar o conhecimento em um tema específico, mas a formação de professores deve se antecipar e repensar o currículo voltado para alfabetizar e letrar.

Afinal, até a quando a formação inicial docente vai ficar na corda bamba, fazendo uma professora iniciante na alfabetização andar como uma equilibrista?

Sabemos que as dificuldades em relação à aprendizagem da docência não giram em torno apenas da formação inicial, tem a ver com políticas públicas, contexto escolar, uma série de fatores que fazem com que a iniciação seja única para cada sujeito. Entretanto, é complicado assistirmos improvisações e tentativas no processo de alfabetização, independentemente da fase de desenvolvimento profissional que o docente esteja vivenciando. Precisamos então mudar o ritmo da canção, trocar os passos e sair da corda bamba.

AGRADECIMENTOS: agência de fomento CNPq.

\section{REFERÊNCIAS}

BOGDAN, R. BIKLEN, S. Investigação Qualitativa em Educação. Lisboa: Porto Editora, 1994.

CARVALHO, M. Alfabetizar e letrar: um diálogo entre a teoria e a prática. 5. ed.

Petrópolis, RJ: Vozes, 2008.

CORSI, A. M. Professoras iniciantes: situações difíceis enfrentadas no início da prática

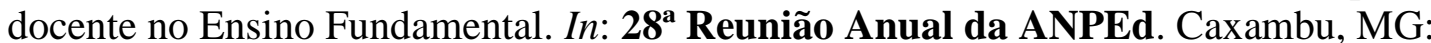
ANPEd, out. 2005. Disponível em: http://www.anped.org.br/reunioes/28/inicio.htm. Acesso em: 12 jul. 2013.

ENGUITA, M. F. A ambiguidade da docência: entre o profissionalismo e a proletarização. Teoria \& Educação, n. 4, p. 41-61, 1999.

GIBBS, G. Análise de dados qualitativos. Tradução Roberto Cataldo Costa; consultoria, supervisão e revisão técnica desta edição Lori Viali. Porto Alegre, Artmed, 2009.

GIOVANNI, L. M. Indagação e reflexão como marcas da profissão docente. In: GUARNIERI, M. R. (org.). Aprendendo a ensinar: o caminho nada suave da docência. 2. ed. Campinas, SP: Autores Associados; Araraquara, SP, 2005.

GONÇALVES, J. A. M. A carreira das professoras do ensino primário. In: NÓVOA, A. (org.) Vidas de Professores. 2. ed. Porto: Porto Editora, 2000. p. 141-197.

GUARNIERI, M. R. Tornando-se professor: o início na carreira docente e a consolidação da profissão. 1996. 157 f. Tese (Doutorado em Educação) - Programa de Pós-Graduação em 
Educação, do Centro de Educação e Ciências Humanas da Universidade Federal de São Carlos, São Carlos, 1996.

HUBERMAN, M. O ciclo de vida profissional dos professores. In: NÓVOA, A. (org.) Vidas de Professores. 2. ed. Porto: Porto Editora, 2000. p. 31-78.

LIMA, E. F. (Org.) Sobrevivências: no início da docência. Brasília: Líber Livro, 2006.

LIMA, E. F. et al. Sobrevivendo ao início da carreira docente e permanecendo nela. Como? Por quê? O que dizem os estudos. Educação \& Linguagem, ano 10, n. 15, p. 138-160, jan./jun. 2007.

MARCELO GARCIA, C. Formação de professores principiantes. In: Formação de Professores: para uma mudança educativa. Porto Editora, 1999. p. 109-132.

MARREIROS, R. S. A. Dos métodos de alfabetização às práticas das professoras: um percurso a ser desvelado. 2011. 127 f. Dissertação (Mestrado em Educação) - Universidade Federal do Maranhão, São Luís, 2011.

MOURA, T. A.; SILVA, G. P. Desenvolvimento profissional docente, PIBID e bonecas russas. Anais do II Congresso Nacional de Formação de Professores e XII Congresso Estadual Paulista sobre Formação de Educação: "por uma revolução no campo da formação de professores", realizado de 7 a 9 de abril de 2014, p. 377-383.

NÓVOA, A. Apresentação da obra. In: NÓVOA, A. (org.) Vidas de Professores. 2. ed. Porto: Porto Editora, 2000. p. 09-10.

PAPI, S. O. G.; MARTINS, P. L. O. As pesquisas sobre professores iniciantes: algumas aproximações. Educ. rev., v. 26, n. 3, p. 39-56, dez. 2010. Disponível em: www.scielo.br/scielo.php?pid=S0102-46982010000300003\&script. Acesso em: 21 abr. 2014.

POWACZUK, A. C. H. A Construção da Professoralidade Alfabetizadora. In: 32 ${ }^{\mathbf{a}}$ Reunião Anual da ANPEd. Caxambu, MG: ANPEd, out. 2009. Disponível em: http://www.anped.org.br/reunioes/32ra/arquivos/trabalhos/GT08-5626--Int.pdf. Acesso em: 30 abr. 2014.

SCHEFFER, A. M. M. Concepções de alfabetização construídas por professoras dos anos iniciais do Ensino Fundamental: as práticas discursivas como eixo de reflexão. 2008. 126 f. Dissertação (Mestrado em Educação) - Universidade Federal de Juiz de Fora, Juiz de Fora, 2008.

SISLA, H. C.; MOURA, T. A. Iniciação à docência: os sabores e saberes desta descoberta. Anais do XVII ENDIPE: a didática e a prática de ensino nas relações entre escola, formação de professores e sociedade, realizado de 11 a 14 de novembro de 2014.

SOARES, M. As muitas facetas da alfabetização. In: Alfabetização e Letramento. 6. ed. São Paulo: Contexto, 2014.

TARDIF, M.; LESSARD, C.; LAHAYE, L. Os professores diante do saber: esboço de uma problemática do saber docente. Teoria \& Educação, v. 1, n. 4, p. 215-233, 1991. 
VEENMAN, S. El proceso de llegar a ser profesor: un análisis de la formación inicial. In: VILLA, Alberto (coord.). Perspectivas y problemas de la función docente. Madrid / Espanha: Narcea, 1988.

VIEIRA, H. M. M. Como vou aprendendo a ser professora depois da formatura: análise do tornar-se professora na prática da docência. Tese (Doutorado em Educação). Universidade Federal de São Carlos, São Carlos, 2002.

\section{Como citar este artigo:}

MOURA, Taís Aparecida de; GUARNIERI, Maria Regina. Uma professora iniciante aprendendo a alfabetizar: processos formativos e saberes docentes na corda bamba. Revista Ibero-Americana de Estudos em Educação, Araraquara, v. 14, n. 3, p. 1001-1014, jul./set., 2019. e-ISSN: 1982-5587. DOI: 10.21723/riaee.v14i3.11552

Data de Submissão: $13 / 07 / 2018$

Revisões requeridas: 10/10/2018

Aceite em: 05/12/2018

Publicado em: 29/03/2019 